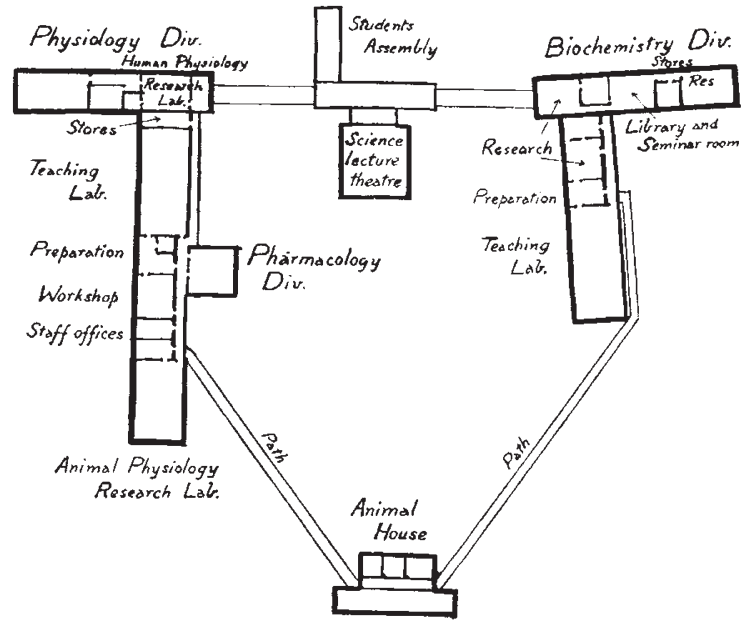

Fig. 2

The teaching of applied physiology will be undertaken when the staffing establishment has been completed.

Because of the location of the new Department in the Caribbean, it was natural that the research interests of its staff would develop in a direction where these territories offer special opportunities. Thus the over-all plan in departmental research has tended largely towards nutritional studies. Several members of the staff, in co-operation with a group from the Department of Pædiatrics from the University of Pennsylvania, are carrying out a basic nutritional survey on children and studying factors influencing nutritional status. We are pleased to report very generous assistance from the American Cyanamid Corporation, Merck and Co. and the Medical Research Council. The nutritional studies have meant an extension of the activities of the Department into relatively inaccessible parts of the island, where villages and communities are only reached after covering long distances, bad roads and surmounting such obstacles as mountain streams, etc. Those of us who have spent most of our time working in the laboratory find this field-work an interesting change. This work has provided material for biochemical studies involving an examination of the metabolism of vitamin $B_{12}$ and a study of the relationship between various enzyme systems and malnutrition. A member of the staff seconded by the Medical Research Council has been studying the intracellular enzymes of the liver and their relation to nutritional deficiencies. Another member of the staff with biochemical interests is now studying the metabolism of the coral reef and carrying out a survey of the zooplankton distribution in these tropical waters.

Jamaica is well supplied with material for the pharmacological and toxicological studies of natural products. Some work has been done on the pharmacological principles in the 'parotid' glands of the local toad (Bufo marinus). Studies have also been carried out on the toxicological principles of a local fruit called the ackee (Blighia sapida), which is a very common item in the Jamaican diet, and is supposed to be responsible for a seasonal disease called 'vomiting sickness'. 'This problem is under investigation with the financial assistance of the Government of Jamaica and in co-ordination with other Departments in the University. Apart from these 'Caribbean' interests, work is continuing on more fundamental physiological problems such as cardiovascular, endocrinological and intra-cellular enzyme studies. One of the pleasing factors of the University College as a whole has been the intimate and close co-operation that exists between the new Department of Physiology and those of other science and medical departments.

All the members of staff live in a housing community close to the laboratories, and a very valuable form of social life has developed in which the staff of the Department meet one evening a week on one another's verandas to read journals and discuss their current research problems. To this club are invited members from other departments with similar interests and any scientists visiting Jamaica.

In its short history the Department has been through fire and water. About sixteen months ago a fire destroyed the temporary animal house. Fortunately nuclei of the various imported animal colonies were saved and in the new permanent buildings we are returning to normal. Very anxious moments arose when flames were sufficiently close to the temporary biochemistry laboratories to cause charring of the external walls. Valuable equipment was moved to a safe distance by many willing hands. Our passage through water occurred one night when 25 in. of rain were blown horizontally by a hurricane through the laboratories. Although the roof of the biochemistry building was torm off, the damage to. equipment was surprisingly small and was soon made good.

\section{THE THYROID GLAND}

$T$ HE Society for Endocrinology and the Endocrinological Section of the Royal Society of Medicine held a joint symposium on "The Thyroid Gland" in London at the Royal Society of Medicine on February 25. This was well attended and covered a wide range of interests. Among the distinguished foreign visitors were Prof. Jean Roche and colleagues from the Collège de France, Paris.

The morning session was opened by the chairman, Sir Charles Harington, who gave a brief review on the development of thyroid research during the past twenty-five years. He recognized a chemical period dating from the characterization of thyroxine, which was followed by a more biological approach resulting from work on the anterior pituitary and its thyrotropic hormone. He referred briefly to recent work on the nature of the thyroid hormone and its biosynthesis. This has depended on the skilful application of chromatography and auto-radiography, particularly by Leblond, Gross, Pitt Rivers and the French team under Prof. Roche. He also dealt briefly with anti-thyroid substances. Although the goitrogens represent at present the only successful therapeutic application in this field, the theoretical importance of thyroxine analogues was mentioned.

Prof. Roche then described in some detail work carried out in collaboration with S. Lissitzky and R. Michel on the mechanisms involved in the biosynthesis of the thyroid hormone. The view was expressed that the iodination of tyrosine occurs after the incorporation of iodine in the thyroglobulin molecule. The circulating blood contains mainly thyroxine with small amounts of $\mathrm{x}$-triiodothyronine ; the absence of mono- and di-iodotyrosine, which occur only in the thyroid, was explained by the operation of a dehalo- 
genase in the gland. Thyroxine is probably converted to triiodothyronine mainly in the peripheral tissues. However, the relative scarcity of triiodothyronine in the blood might also be accounted for by its more rapid excretion.

Mrs. R. Pitt Rivers outlined briefly the methods which she has recently used in collaboration with Dr. J. Gross in the identification of triiodothyronine as a significant part of the thyroid secretion. She then dealt in detail with the physiological activity of triiodothyronine, which possesses all the actions of thyroxine but appears to be about five times as active on a molar weight basis. The same ratio is obtained by different methods of assay such as goitre prevention in rats, the growth-rate of thyroidectomized rats and the minimum dose required for the control of symptoms in patients with myxœdema. 'The D-isomer of triiodothyronine is, however, almost inactive. Mrs. Pitt Rivers felt that L-triiodothyronine is the substance responsible for the peripheral actions of the thyroid hormone. In the discussion, Dr. G. H. Deltour reported similar results on twelve patients with myxoedema treated with triiodothyronine, and Dr. J. C. Gilliland said that triiodothyronine is more effective than thyroxine in depressing thyrotropic hormone output in the chick. Dr. S. J. Folley, on the other hand, said that he has failed to find any influence of triiodothyronine on the milk yield of cows whereas thyroxine is effective in this connexion. In reply to Mrs. Pitt Rivers, he agreed that the more rapid excretion of triiodothyronine might be of importance here.

The occurrence of post-operative myxœedema in a group of 570 patients, followed over a three-year period, has been studied by Dr. Raymond Greene. The results have been correlated with the histological appearance of the glands, and a strong correlation appears to exist between the presence of lymphoid nodules and the subsequent development of myxœdema. He said that he has formed the opinion that in the absence of lymphoid nodules no ordinary sub-total thyroidectomy will produce myxœdema, and that this complication depends almost entirely upon the state of the gland before operation. The series includes a substantial number of cases of Hashimoto's disease, but even excluding these the relationship still holds. In the discussion Prof. J. M. Yoffey stressed the possible influence of the adrenals in relation to lymphoid hyperplasia.

Mr. S. L. Hignett described a syndrome in cows consisting of thyroid enlargement and a tendency of masculinization as shown by the development of the neck muscles and the attitude of the tail. This is associated with diminished fertility and appears to present a certain analogy with the adreno-genital syndrome in man.

The last speaker in the morning session, Prof. N. F. Maclagan, gave a short account of recent work on the anti-thyroxine compounds. Most of these compounds are iodinated phenols resembling portions of the thyroxine molecule, and have aroused interest since 1946, when Woolley showed that the effects of thyroxine on tadpole metamorphosis could be antagonized by compounds of this type. The most active compound synthesized in his department was $n$-butyl 4-hydroxy-3:5-diiodobenzoate. This is an effective thyroxine antagonist in animals and has been tried clinically in association with Dr. Russell Fraser. It cannot, however, be administered to patients in dosages high enough to produce unequivocal anti-thyroxine effects. Results obtained in collaboration with Dr. Wilkinson and Mr. Sprott were then reported, showing that it augments the metabolic action of triiodothyronine in mice and inhibits the deiodination of $\mathrm{L}$-diiodotyrosine in rats. These results support the hypothesis that the compound acts by inhibiting the deiodination of thyroxine and of triiodothyronine. Exact information about this deiodination is not, however, at present available. In the discussion, Mrs. Pitt Rivers and Prof. Roche agreed that these compounds probably are deiodinated in the animal body, although the site of this process is uncertain.

In the afternoon the chair was taken by Dr. S. Leonard Simpson, and Dr. W. R. Trotter opened with some observations on the natural history of Graves's disease as revealed by treatment with antithyroid drugs of the thiouracil type. He has found a significantly greater relapse-rate in patients treated for less than one year as compared with those treated for more than one year. He thought that patients who have relatively brief episodes of thyrotoxicosis are particularly liable to have one or more subsequent episodes. A further study of the patients has shown that relapses under treatment are significantly more frequent in winter and spring than at other seasons in the year. The factors concerned in this seasonal relationship are obscure, and Dr. Trotter is not impressed with the influence of psychological stress. In the discussion the influence of hot weather and of sunburn were mentioned; but no clue to this seasonal variation was forthcoming.

The next paper, on thyroid activity in the rabbit, by G. W. Harris, C. von Euler, J. Brown-Grant and S. Reichlin, was read by Prof. Harris. He described a technique employing iodine-131 which he thought gives a measure of the output of hormone by the gland over a period of some weeks. The exposure to cold and administration of thyrotropic hormone increase the rate of output, whereas confinement in the dark, thyroxine, and adrenocorticotropic hormone diminish the rate of output. This hormone is thought to produce its effect via the output of the thyrotropic hormone by the pituitary. In the discussion Dr. Russell Fraser directed attention to the need for a further analysis of emotional factors. $\mathrm{H}_{\theta}$ thought that, while fear does not cause thyroid stimulation, other emotional stimuli may do so. Dr. M. Reiss described the inhibitory effect of adrenalin on thyroid function, and Dr. Trotter expressed some doubts as to the interpretation of the release curves shown.

Dr. A. Stuart Mason reviewed methods for assaying the thyroid-stimulating hormone and presented some results on uptake of phosphorus-32 by the thyroid. He thought that this method is complementary to those involving iodine-131, as it is dependent upon hyperplasia rather than hyperfunction. Experiments with iodide suggest that its effect is produced by inhibiting pituitary secretion of thyroid-stimulating hormone rather than by action on the thyroid gland. Prof. Roche expressed his interest in the method and speculated upon its possible relation to mechanisms involving energy-rich phosphate bonds and the biosynthesis of thyroglobulin.

Dr. Russell Fraser spoke of the need for laboratory tests for thyrotoxicosis. While the diagnosis is obvious in perhaps 30 per cent of cases, more frequently it is to some extent a matter of opinion, and objective evidence of hyperfunction is of great value. He thought that measurements involving 
iodine-131 probably include the best single tests at present available, and, while methods involving the output of hormone as described by Prof. Harris are useful in animals, for clinical work all successful tests depend upon uptake of iodine-131 by the gland. Fortunately the uptake is usually equal to the output in the untreated patient. The method employed at the Postgraduate Medical School of London depends upon measurement of urinary radioactivity and the calculation of a $T$ factor. Dr. Fraser's results show that this test is highly efficient in the diagnosis of thyrotoxicosis. It is not quite so good in cases of doubtful myxœdema, although classical cases always give low values. After treatment with goitrogens, the intake is no longer equal to the output, and the position is complicated by iodine deficiency. The test can usefully be employed threo months after therapeutic doses of iodine-131.

Results illustrating the diagnostic value of serum protein-bound iodine estimation in the diagnosis of thyroid disorders were described by Dr. R. R. de Mowbray, who said that he cannot agree with some previous claims and has found high values in only 62 per cent of patients with hyperthyroidism. In hypothyroidism, results are below normal in 85 per cent of cases. High levels are seen in normal pregnancy. The overlap with normal values is a definite limitation to the usefulness of this test, but it nevertheless has its value, particularly in the case of patients intolerant of the estimation of basal metabolic rate. Mr. A. Tickner, who joined Dr. de Mowbray in this paper, then described some of the laboratory hazards of the estimation. $\mathrm{He}$ also reported some results with serum cholinesterase estimation in thyrotoxicosis. Although high values are frequently obtained, the estimations are of little diagnostic value.

The chairman, Dr. Leonard Simpson, wound up the symposium with a short summary, in which he said that he was particularly impressed with the application of chromatography and the use of radioisotopes in this field. As a clinician he thought that the relationship of the thyroid with other endocrine glands would repay much further study, and he gave a number of examples illustrating these relationships. $\mathrm{He}$ hoped that a later symposium might help to explore these other endocrine relationships.

\section{METHODS OF PLANT PEST AND DISEASE ASSESSMENT}

$\mathrm{T}$ HE meeting of the Association of Applied Biologists at Imperial College, London, on February 27 was devoted to a symposium on the assessment of plant pests and diseases. In the opening paper, Mr. E. C. Large, of the Ministry of Agriculture's Plant Pathology Laboratory at Harpenden, referred to the wealth of information ${ }^{1}$ on plant diseases in England and Wales that had been extracted from monthly reports sent to the Laboratory since 1917, and gave an account of some of the recent surveys, undertaken jointly by the Laboratory and the National Agricultural Advisory Service, to supplement the reporting service and obtain more quantitative information on the losses caused by plant diseases throughout the country. Mr. Large described the way in which an investigation on potato blight forecasting ${ }^{2}$, begun in $\mathbf{1 9 5 0}$ in collaboration with the
Agricultural Branch of the Meteorological Office, had been developed into a comprehensive survey for both outbreak dates and progress of blight. From the survey maps and curves for the progress of blight on the foliage, taken in conjunction with the results of spraying trials at key centres, it would be possible within a few years to give reliable estimates of the mean gain, or loss, to be expected from routine protective spraying in each region of the country ${ }^{3}$. Disease-assessment (or, as Mr. Large now calls them, 'plant pathometric') methods applied in potato haulm destruction trials at twelve centres over a period of three years were also clearly revealing the blight conditions under which haulm destruction was, and was not, of value for the prevention of the disease in the tubers ${ }^{4}$. Other investigations in progress included a survey of Epichloe typhina attack on cocksfoot seed crops $^{5}$, now in its third year ; a survey of common scab in potatoes, begun in 1952 in collaboration with the Potato Division of the Ministry of Food; and a survey of clover rot in crops of broad red and lateflowering clover, begun in 1953.

The second paper, by Dr. H. E. Croxall (N.A.A.S. Provincial Headquarters, Newcastle upon Tyno), described joint work with D. C. Gwynne and J. E. E. Jenkins in devising rapid methods for assessing the damage caused by apple diseases, particularly apple scab (Venturia inoequalis) and brown rot (Sclerotinia fructigena). Apple scab damage on the foliage might be conveniently expressed in terms of mean percentage area of the leaves covered by lesions. This could be calculated by comparing leaf samples with standard diagrams showing the appearance of individual leaves with known percentage areas covered by scab. This method was too time-consuming for rapid survey work, and from it had been derived a word-picture key in which brief descriptions were given of the appearance of branches on which the leaves had a known amount of scab damage. In a limited number of tests this method had given results of the same order as those obtained by the standard diagram method.

Similar keys had been drawn up for assessing the amount of scab blemishes on the fruit before picking and also the loss in crop due to brown rot. The results achieved so far were reasonably in agreement with those obtained by a sampling technique using standard diagrams. The possibility of correlating the mean percentage area of fruit covered by scab lesions with the grading of fruit according to the recommended grades of the Ministry of Agriculture Marketing Division was now being investigated. Methods were also being developed for giving a direct estimate of loss of value due to scab in samples of apples after picking.

Dr. R. Hull, of the Rothamsted staff (Dunholme Field Station), dealt with the records of sugar beet diseases made each year by the agricultural staff of the British Sugar Corporation under a scheme organized at Dunholme. Counts of virus yellows in sample fields were checked against yearly estimates of the acreage affected at the end of August. The disease had built up from low levels over four-year periods to peak infections in 1945 and 1949 when more than 50 per cent of the crop was infected. The weather in 1952 had been very favourable for aphid development and movement, and a severe attack of the disease developed late in the season. The losses caused by the disease were assessed by allocating an experimentally determined loss of 4-5 per cent of sugar yield for each week during which plants showed 